\title{
A mini review on percent time-spent-following (PTSF) as the service measure for two-lane highways
}

\author{
Rama Rizana ${ }^{\mathrm{a}^{*}, \text { Wael Alhajyaseen }}{ }^{\mathrm{b}}$ \\ ${ }^{a}$ Civil and Environmental Engineering Department, King Fahd University of Petroleum and Minerals, Dhahran, 51261, Kingdom of Saudi Arabia \\ ${ }^{b}$ Qatar Transportation and Traffic Safety Center, College of Engineering, Qatar University, P.O.Box 2713, Doha, Qatar
}

Article history:

Received: 19 April 2018 / Received in revised form: 13 October 2018 / Accepted: 19 October 2018

\begin{abstract}
Percent Time Spent Following (PTSF) is used by the Highway Capacity Manual (HCM) as one of the service measures to assess the level-ofservice of two-lane highways since the 2000 edition. But, the problem facing to estimate this parameter is that the difficulty to measure it directly in the field. From several studies, it is known that the HCM analytical procedures applied in PTSF estimation produces inconsistent results with the $3 \mathrm{~s}$ surrogate measure and most of them are overestimate. This paper presents a review on estimating PTSF on two-lane highways from several studies that adopted HCM procedures.
\end{abstract}

Keywords: two-lane highways; service measure; PTSF

\section{Introduction}

Two-lane highways take the big number of highways in the world. Traffic flow on two-lane highways is different from other type of roads, mainly because vehicles traveling on the lanes are facing oncoming traffic on the opposing lane and they may be subject to delay because they are not able to pass slow moving vehicles. Vehicular interactions in the traffic stream also characterize it, not only in the same direction of movement, but also in the opposing one. This will lead to the formation of platoons as for a fast-moving vehicle to pass a slow moving one safely, it requires the use of opposite travel lane that depends on enough sight distance and allowed gap in the opposing lane.

The Highway Capacity Manual introduced Percent Time Spent Following (PTSF) on the 2010 edition as one of the most important performance measures to the level-of-service (LOS) for two-lane highways. PTSF is the ratio between the time spent in platoons and the total travel time and is expressed in percentages [1]. It can also be defined as the average percentage of the travel time that the vehicles must spent to travel in platoons behind slower vehicles, because they are unable to pass [2-3].

Other performance measures had been used on the previous editions of HCM; HCM 1950 and HCM 1965 of the Highway Research Board (HRB), and HCM 1985 of the Transportation Research Board (TRB) that passed through some revisions as discussed by Luttinen [4]; Al-Kaisy and Karjala. Among the some revised service measures, percent time delay (PTD) was

* Corresponding author. Tel.: +966545787036

Email: ramarizanast@gmail.com the one nearly related to PTSF. PTD is defined as the average percent of travel time that all vehicles are delayed while traveling in platoons due to inability to pass (HCM, 1985). It was known that it was so difficult to measure directly from the field observation; then, it was recommended that the vehicles proportion traveling at headways less than $5 \mathrm{~s}$ as surrogate measure for its field measurement (HCM, 1985). Even though PTD had been used for two-lane highways in the operational analysis, other studies gave report that the use of $5 \mathrm{~s}$ headway is not consistent with field data [5-9].

Guell and Virkler [5] suggested that 5-s headway criterion should be revised to a range of 3.5 to $4 \mathrm{~s}$ would provide more reasonable, regular results and more useful LOS classes. Another similar study in Canada said that PTD resulted from HCM 1985 procedures are higher than those observed in the field (Krumins and TAC, 1991). Johnson [6] suggested 2.5-s criteria as cut-off headway for platooning vehicles as against the 5-s surrogate measure for PTD which produced unacceptable results.

A study conducted by Al-Kaisy and Durbin [9] reported that interaction between successive vehicles headway threshold value that fell in the range of 5-7 s. It was known from the study that very short headways (less than one second) are more associated with aggressive driving and higher speeds than that with slow-moving platoons because the lack of passing opportunities.

\section{Symbols}

The scientific symbols used in this paper are described in Table 1. 
Table 1. Symbols used in the paper

\begin{tabular}{ll}
\hline \multicolumn{1}{c}{ Symbol } & \multicolumn{1}{c}{ Description } \\
\hline$v_{p}$ or $q$ & $\begin{array}{l}\text { Two-way passenger-car equivalent flow rate for peak } \\
\text { 15-minutes period (pc/h) }\end{array}$ \\
PTSF $F_{d}$ & $\begin{array}{l}\text { Percent time-spent following in the direction analysis } \\
\text { Passenger-car equivalent flow rate for the peak 15-min } \\
v_{d}\end{array}$ \\
$f_{d / n p}$ or $f_{n p}$ & $\begin{array}{l}\text { Adjustment for percentage of no-passing zones in the } \\
\text { combined directional distribution of traffic or analysis } \\
\text { direction respectively }\end{array}$ \\
& $\begin{array}{l}\text { Coefficients used in estimating percentage time-spent } \\
\text { following for directional segments }\end{array}$ \\
$F, b, c$ & $\begin{array}{l}\text { Proportion of vehicles with headway less than } 3 \mathrm{~s} \text { for } \\
\text { both directions of traffic }\end{array}$ \\
\hline
\end{tabular}

\section{Review of PTSF as Service Measure}

In HCM 2000, PTSF was estimated by using two-way and directional analysis, while PTSF in 2010 was estimated by using only directional analysis approach. HCM, 2000 uses Eq. 1 and Eq. 2 for two-way and directional analyses respectively, while HCM 2010 uses Eq. 2 for the directional analysis.

$$
\begin{gathered}
\text { PTSF }=100\left\{1-e^{-0.000879 v_{p}}\right\}+f_{d / n p} \\
P T S F_{d}=100\left\{1-e^{a v_{d}^{D}}\right\}+f_{n p}
\end{gathered}
$$

Luttinen [4] studied the capacity and level-of-service on Finnish two-lane highways. That study used proportion of vehicles with headways less than $3 \mathrm{~s}$ to estimate PTSF values. He examined PTSF with 80 and $100 \mathrm{~km} / \mathrm{h}$ speed limits. The result from study was lower than suggested by HCM 2000. Moreover, PTSF values on roads with $100 \mathrm{~km} / \mathrm{h}$ speed limit were slightly higher than on $80 \mathrm{~m} / \mathrm{h}$ speed limit roads. Eq. 3 is the exponential headway model proposed by that study based on flow rates, geometric and other operational characteristics. That equation was also developed in the study based on the principle that vehicular headways in random flow will follow a negative exponential distribution. Both models resulted lower PTSF values compared to two-way analytical model given in HCM 2000 that supports the inconsistency among the estimates methods as shown in Fig. 1.

$$
F(3 / q / 2)=100\left(1-e^{-q / 2400}\right)
$$

Polus and Cohen [11] estimated PTSF in Israel based on the number of headways both inside and outside platoons. Vehicles were only considered inside platoon when their headway is less than $3 \mathrm{~s}$, otherwise they are outside platoon. PTSF is estimated by using Eq. 4 after being calibrated according to the best-fit method.

$$
P T S F=100\left\{1-e^{-0.000504 v_{p}}\right\}
$$

PTSF estimates resulted in these studies were found to be greatly lower than those resulted using the HCM 2000 two-way analytical procedure as shown in Figure 1. Same study was again conducted in the same country by Cohen and another of his friend [1]. They estimated PTSF based on average number of headways between and outside platoon on the basis of $3 \mathrm{~s}$ cut-off headway derived from vehicles arrival times. The authors assumed that overtaking opportunities were not impeded by no-passing zones. They proposed a relationship between PTSF and two-way flow rate. The result indicated that the values resulted from the proposed model were considerably lower than the values from HCM 2000 model.

Although both studies were held on the same country based on similar local and traffic conditions, the results from the first study [11] resulted higher PTSF compared to the second study [1] that passing opportunities along the roads are not impeded by no-passing zones (assuming the effect of no-passing zones was neglected while developing the model).

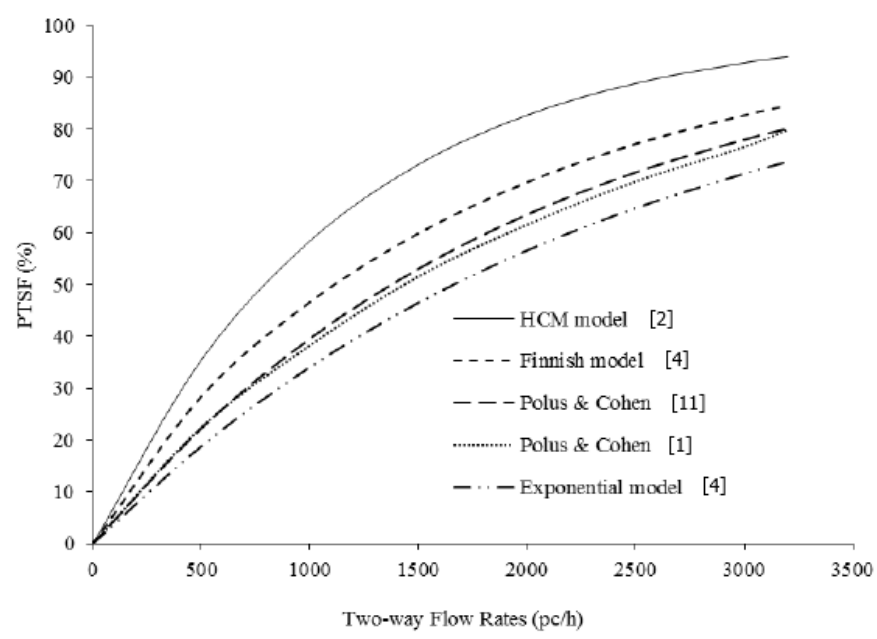

Fig. 1. PTSF estimates using two-way model compared to field observed values using 3-s according to Ibrahim et al. [12]

Polus and Pollatschek [13] studied to evaluate flow characteristics on two-lane rural highways and to develop criteria for highway widening. The study was divided on two tracks: theoretical development of delay models and use of a simulation model to estimate the effect of certain parameters on delay and percent-time-spent following. Fig. 2 shows the percent-time-spent following for two-way direction hourly volumes and different average speeds in the main direction compared to the HCM 2000 model. It can be concluded from the difference is small, and the HCM model fits closer to the higher speed $(100$ and $110 \mathrm{~km} / \mathrm{h})$ in the low-volume range, and better for the lower speeds ( 60 and $70 \mathrm{~km} / \mathrm{h}$ ) in the high volume range.

Bessa and Setti [14] adapted HCM 2000's PTSF functions for two-lane rural highways in Brazil. Traffic data were collected from 11 locations, capturing a wide range of traffic data. The HCM 2000 functions were recalibrated using the synthetic data that obtained by creation of Genetic Algorithm (GA during the calibration of TWOPAS. The proposed model from this study is shown in Eq. 5.

$$
P T S F_{d}=100\left[1-a \cdot e^{-b \cdot q^{c}}\right]
$$

where $a, b, c$ constants are obtained from the proposed model structure.

Based on the several studies mentioned in this paper, it is known that there will be inconsistent values resulted from the HCM analytical and field observation of PTSF.

Extract of PTSF estimation by the HCM 2010 [3] analytical procedure relative to field data $[4,11,14]$ is shown in Table 2, while Table 3 shows the difference of whether overestimate or underestimate from the results given in Table 2 . The result showed that even at the same number of flow rates, the 
overestimation level differs from one study to other, except in the study conducted by Bessa \& Setti [14], there are underestimation compared to HCM 2010. For all calculation, it was assumed that $0 \%$ no-passing zones to make f_np estimation become easier.

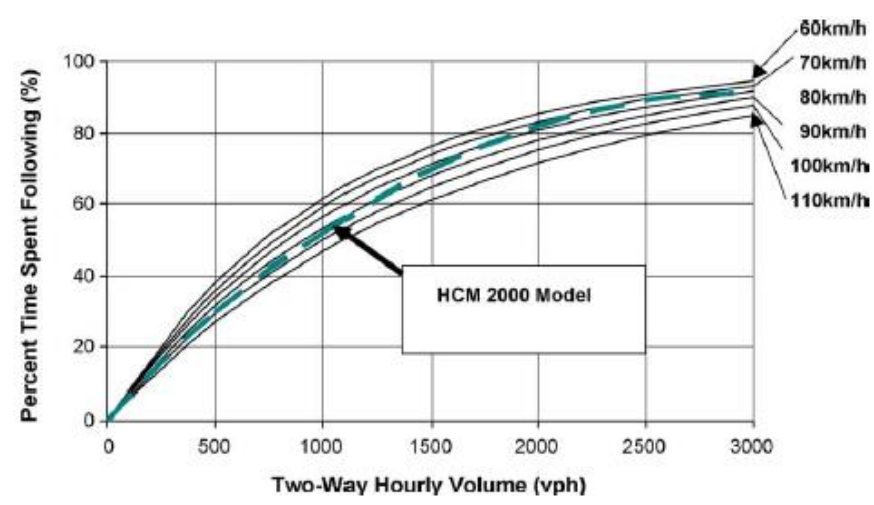

Fig. 2. Percent-time-spent-following for different main-direction speeds and for a range of two-way hourly volumes assumes equal volumes in both directions according to Polus and Pollatschek [13]

Table 2. PTSF estimation (\%) of several models

\begin{tabular}{llll}
\hline \multirow{2}{*}{ Study } & \multicolumn{3}{c}{ Two-Way Flow Rates (pc/hr) } \\
\cline { 2 - 4 } & $\mathbf{1 0 0 0}$ & $\mathbf{2 0 0 0}$ & $\mathbf{3 0 0 0}$ \\
\hline HCM 2010 [3] & 58.86 & 82.77 & 92.94 \\
Exponential model [4] & 34.08 & 56.54 & 71.35 \\
Polus \& Cohen [11] & 39.59 & 63.50 & 77.95 \\
Bessa \& Setti [14] & 67.77 & 87.20 & 93.65 \\
\hline
\end{tabular}

Table 3. Approximate overestimation (\%) of PTSF by HCM 2010 model analysis to field values for several flow rates

\begin{tabular}{lccc}
\hline \multirow{2}{*}{ Study } & \multicolumn{4}{c}{ Two-Way Flow Rates (pc/hr) } \\
\cline { 2 - 4 } & $\mathbf{1 0 0 0}$ & $\mathbf{2 0 0 0}$ & $\mathbf{3 0 0 0}$ \\
\hline Exponential model [4] & 42 & 32 & 23 \\
Polus \& Cohen [11] & 33 & 23 & 16 \\
Bessa \& Setti [14] & -15 & -5 & -1 \\
\hline
\end{tabular}

Likewise, the directional analysis procedure produced in PTSF values overestimated compared to field observation results. PTSF values from study conducted in South Africa [15] based on field observation and developed model (Figure 3) were also able to be compared with those of other studies mentioned earlier.

Even under USA conditions where the HCM 2000 edition and 2010 edition were developed, studies in Idaho [16] and Montana [17] reported significant differences in estimating PTSF between analytical and field measurements.

Threshold Speed, the lowest speed drivers consider satisfactory while traveling on a uniform section of a road under heavy and platooning traffic. It is based on user perception and good judgment. The advantage is the easiness to measure. However, it is difficult to assign a particular cutoff speed acceptable to all users.

Average Travel Speed (ATS) is assigned as one of key measures used by the HCM. IT is considered as a good performance indicator for two-lane roads, and well related to the user perception and easy to measure. However, the lack of specific yardstick across the performance level due to variations in two-lane highways in terms of geometry and operating speeds is the drawback.

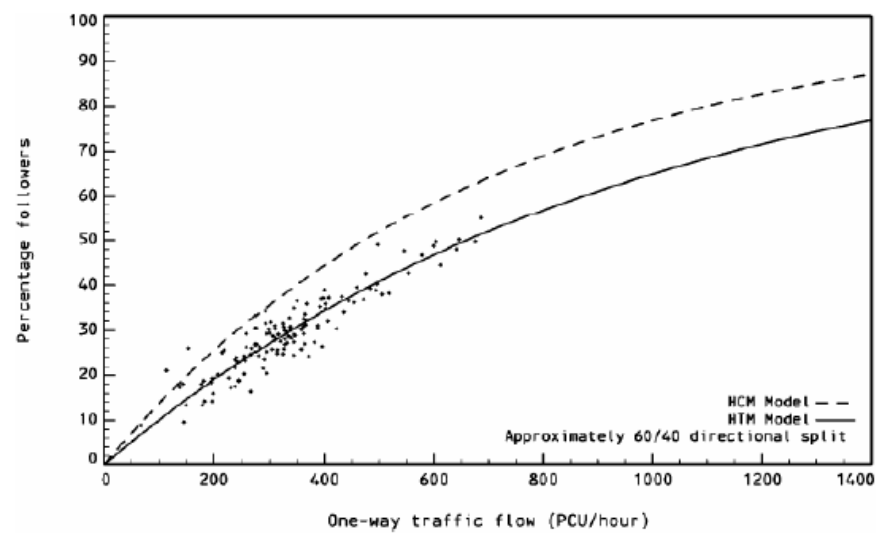

Fig. 3. Comparison of PTSF estimates using directional analysis and field values using $3 \mathrm{~s}[15]$

Percent Followers (PF), indicates the proportion of vehicles with short headways in the traffic stream. It can be measured using the same way suggested by HCM $\square$ using $3 \mathrm{~s}$ criterion. It does not reflect the effect of traffic level which is a vital condition in HCM LOS concept. The use of PF alone could be misleading [18].

Moreno et al. (2014) conducted study to calibrate 10 performance measures for two-lane rural highways. The studied performance measures included: ATS, ATSPC, PFFS, PFFSPC, Percent Follower (PF), Follower Density (FD), Percent Impeded (PI), and Average Platooning Length (APL). Traffic density and freedom of flow. Both directional and twoway analyses were considered. The results showed that the FD had the strongest correlation with traffic variables, with a coefficient of correlation of $94 \%$ [19].

\section{Conclusion}

Estimating PTSF for two-lane highways using HCM procedure is criticized by many researchers, not due to its inadequacy as performance indicator; but because it is hard to obtain directly from the field measurement. Also, the analytical procedures and use of $3 \mathrm{~s}$ criteria for field observations were known to result inconsistent values. The result from analytical procedures significantly overestimate the values from the field measurement.

Because PTSF is travel time related measure, the most suitable way to evaluate the parameter along a road segment is to employ the use of observer(s) within the traffic stream under study. This could be achieved through the use of test vehicle (moving car observer) technique. Because of that, Mutakka et al. [12] suggested to use of test vehicle approach over the road segment to be evaluated to identify the variables that are needed to develop a representative measurement model.

Most of studies mentioned in this paper, adapted the HCM 2000 [2], while in HCM 2010 [3] there is a change in analyzing the two-lane highway based on one-direction instead of twoway analysis in HCM 2000. Hence, it needs to study regarding that change and adapted to the real condition in other areas or countries. 


\section{Acknowledgements}

The author thanks to Civil and Environmental Engineering Department, King Fahd University of Petroleum and Minerals (KFUPM).

\section{References}

1. M. Cohen and A. Polus, Estimating percent-time-spent-following on twolane rural highways, Transp. Res. Part C Emerg. Technol. 19 (2011) 1319 1325.

2. TRB, Highway Capacity Manual, 4th Editio. Washington D.C.: National Research Council, 2000.

3. TRB, Highway Capacity Manual, 5th Editio. Washington D.C.: National Research Council, 2010.

4. R. Luttinen, Percent time-spent-following as performance measure for two-lane highways, Transp. Res. Rec. 1776 (2001) 52-59.

5. D. L. Guell and M. R. Virkler, Capacity analysis of two-lane highways, Transp. Res. Board Natl. Acad. 1194 (1988) 199-205.

6. G. Johnson, Highway capacity manual misses mark on rural highway capacity, in Compendium of Technical Papers, Institute of Transportation Engineers 65th Annual Meeting, Denver, 1985.

7. I. Krumins and TAC, Two-lane highway capacity and level of service research project: Phase III final report, Ottawa, 1991.

8. R. Luttinen, Statistical properties of vehicle time headways, Transp. Res. Board 1365 (1992) 92-98.
9. A. Al-Kaisy and C. Durbin, Platooning on two-lane two-way highways: An empirical investigation, Procedia Soc. Behav. Sci. 16 (2011) 329-339.

10. G. M. Romana and I. Perez, Measure of effectiveness for level-of-service assessment of two-lane roads: an alternative proposal using a threshold speed, Transp. Res. Rec. 1998 (2006) 56-62.

11. A. Polus and M. Cohen, Theoretical and empirical relationships for the quality of flow and for a new level of service on two-lane highways, J. Transp. Eng. 135 (2009) 380-385.

12. N. I. Muttaka, C. P. Othman and M. Mushairry, Review of percent time spent following (PTSF) as performance measure for two-lane highways, J. Teknol. 64 (2013) 9-18.

13. A. Polus and M. A. Pollatschek, Criteria for widening of two-lane rural highways, Transp. Policy 11, (2004) 379-385.

14. J. E. Bessa and J. R. Setti, Derivation of ATS and PTSF functions for twolane, rural highways in Brazil, Procedia Soc. Behav. Sci. 16 (2011)282292

15. C. Van As. and A. Van Niekerk. The operational analysis of two-lane rural highways, 23rd Southern African Transport Conference in South African Highway Capacity Research, 2007.

16. M. P. Dixon, S. S. K. Sarepali and K. A. Young, Field evaluation of highway capacity manual 2000 analysis procedures for two-lane highways, Transp. Res. Board 1802 (2002) 125-132.

17. A. Al-Kaisy and C. Durbin. Estimating percent time spent following on two-lane highways: field evaluation of new methodologies. 2007.

18. M. Shawky and I. Hashim, Impact of horizontal alignment on traffic performance at rural two-lane highways, in 4th International Symposium on Highway Geometric Design, 2010.

19. A. T. Moreno., C. Llorca, T. Sayed and A. Garcia, Field evaluation of traffic performance measures for two-lane highways in spain, Transp. Res. Circ. E-C190 (2014) 71-87. 